\title{
Transformative Critical Leadership in Action: Re-visioning an Equity Agenda to Address the Community College Achievement Gap
}

Lorri J. Santamaría, Ph.D.

The University of Auckland, New Zealand

\begin{abstract}
This conceptual article summarizes the call for transformative critical leadership in education and provides an overview of the equity agenda in response to the identified academic achievement gap in community colleges nationwide. It offers educational leaders in higher education applied and feasible strategies for increasing critical communication with educators, community members, and stakeholders interested in re-visioning core tenants of equity agendas at the community college level. The chapter also suggests the consideration of critical leadership as an emergent type of transformative leadership practice involving the facilitation of crucial conversations to incite change as well as policy implications.
\end{abstract}

Academic achievement gaps separating culturally and linguistically diverse learners in our nation's $\mathrm{K}-12$ schools from their White peers have drawn the attention of educational leaders and policy makers and brought forward fiscal resources (California Department of Education, 2007; Darling-Hammond, 1999, 2007; Vanneman, Hamilton, Anderson, Rahman, \& National Center for Education Statistics, 2009). Although gaps in dropout rates are frequently reported, few scholarly contributions have been made in relation to students on community college campuses and to the national equity agenda designed to protect them from inequities (Mullin, 2011; Nevarez \& Wood, 2010). Educational researchers have acknowledged the need for practical transformative models to address educational disparities (Capps, Fix, Murray, Passel, \& Herwantoro, 2005; CDE, 2007; Darling-Hammond, 2007). Educators are also beginning to understand that unequal distribution of power and cultural capital at institutional levels may very well result in some gaps, particularly at the community college level
(Anyon, 2009; Bailey \& Morest, 2006; Capps et al., 2005; Goldenberg, 2008; Lum, 2009; Mullin, 2012b; Nevarez \& Wood, 2010).

This article complements Nevarez and Wood's (2010) Community College the Achievement Gap model by providing educational leaders at the community college level with key facilitation processes to re-conceptualize the equity agenda through meaningful structured conversation designed to transform communities' perceptions regarding racial and cultural inequities into positive action. Using the principles of applied critical leadership and informed purposeful facilitation, the strategy has the potential to result in context specific equity agendas as a response achievement gaps in community colleges nationwide.

\section{The Equity Agenda in Higher Education}

Higher education equity can be considered on three levels, one leading to the other: college preparation, access to college, and, finally, success in reaching college goals (Bailey \& Morest, 2006). 
Unfortunately, whether students are prepared, have access, and experience success depends far too often on income or race and ethnicity, and the situation is not getting better: "Political, fiscal, demographic, and technical trends over the past 15 years have introduced new barriers to the postsecondary equity agenda" (Bailey \& Morest, 2006, p. 2). According to Bailey and Morest (2006), these barriers include increased tuition, demographic growth, outcomes-based accountability, competition among higher education institutions, and growing technological demand by employers. "These findings are even more pronounced for students of color" (Mullin, 2011, p. 4). Moreover, lowincome students in community college have a greater proportion of various risk factors when compared to other students in higher education (Mullin, 2012b). In addition, these gaps are compounded by sociopolitical and business trends, which distract community college leadership from focusing on preserving equity agendas developed over a decade ago.

Over time researchers have concluded that classroom educators are the single most important factor with regard to student achievement (Archibald, 2006; Darling-Hammond, 1999; Yoon, Duncan, Lee, Scarloss, \& Shapley, 2007). We now know that language, culture, race, ethnicity, and socioeconomic status matter in terms of student preparation before they enter school and in terms of the ways in which students perform from pre- kindergarten through high school, carrying over into their performance in higher education (Archibald, 2006; Dunn, Honigsfield, \& Doolan, 2009; Huang \& Moon, 2009, Mullin, 2012a). We also know that there are ways to incrementally decrease academic and other gaps, but with scant research and literature supporting these practices, we have seen an uneven application of best practices across the board. Perhaps most importantly, the research that does exist substantiates the reality that all individuals can learn under optimal conditions (Cochran-Smith, 2008; Mullin, 2012a).

\section{Gap persistence}

Forces have been identified that sustain gaps separating learners at the community college aside from the effects of inequitable institutional resources impacted by various revenue streams. One is the reality of institutional racism leading to educational inequities (Ladson-Billings, 2010). The second is a rapidly changing demographic population, which contrasts starkly with instructors and administrators in community colleges across the country (Bowen, Chingos, \& McPherson, 2009). The third are antiquated instruction and leadership practices that do not complement the challenges of 21 st century community college education in United States of America (Kasper, 2003; Levin \& Montero-Hernandez, 2009). Furthermore, low-income community college students may not have time to engage in the college experience as compared to students from more affluent families (Mullin, 2012a). This time barrier, according to Mullin, 2012a, may result in the need for community college educators and leaders to be more deliberate in the provision of opportunities and access to all students and value lowincome student time spent on campus. The challenges are so great that early retirements are being reported at every level from instructional assistant, to instructor, and to community college administrators (Bailey \& Morest, 2006; Nevarez \& Wood, 2010).

However, recent increases in scholarly attention to innovative applications of transformative leadership, investigation of cultural competence, and the application of courageous conversation as tools enable educators to examine and change inequitable educational practices (Lindsey, Robins, \& Terrell, 1999; Santamaría \& Santamaría, 2011; Santamaría, Santamaría, \& Fletcher, 2009; Shields, 2010; Singleton \& Linton, 2006; Wheatley, 2002). Perhaps this trend may be useful in community college settings where redirection toward the equity agenda is essential. Educators agree that large-scale educational change ultimately requires educators at every level to make micro-decisions about their pedagogy and practice based on individual educational contexts, local district and school culture, the demographics of the community in which they work, and the particular circumstances associated with unique educational challenges. Engaging in courageous conversations and posing critical questions have been identified as practical institutional means to approach challenges in education around real goals such as equal outcomes for every student. However both of these approaches require skilled facilitation, practice, and time to achieve 
results. So, where do we go from here?

Providing a means for large-scale institution wide conversations with colleagues about race is critical when educators are involved in taking action on issues related to racial inequality. Singleton and Linton (2006) and others have given us a blueprint for such conversations. We apply this work to provide a way for educational leaders to begin critical discussions on institutional levels about ways in which race impacts student achievement (Wheatley, 2002). Another approach to reaching consensus is called the World Café (Brown \& Isaacs, 2005). This approach works with large or small groups to identify next steps for the group to take in unity and with focus.

The implementation of structured conversations like World Café is discussed in the remainder of this article. The call for critical leadership requires implementation of such strategies. This discussion is followed by an examination of policy implications for the creation of an equity agenda to address the community college achievement gap.

\section{The Role of Conversation}

Wheatley (2009) reminded us that simple conversation has the potential to restore hope to our future:

Talking and listening to one another is something we remember; it's what humans have done for thousands of years, so it's deep in our species' memory. These days, because of the bad habits we've developed and the frantic pace of our lives, we may need to be reminded about slowing down, not interrupting, listening to each other and not instantly responding. (p. 10)

Educators in general have become like clinical scientists-busy collecting data, analyzing results, and reporting findings. We have ascribed to these practices so much that we have forgotten to engage one another in critical conversations specifically with regard to race, culture, ethnicity, linguistic background, socioeconomic status, and gender, and the ways in which these factors contribute to academic achievement for students in postsecondary educational settings. Nevarez and Wood
(2010) argued that background, personal, and social factors contribute more to achievement gap indicators than do institutional factors and macro support for the institution. These are factors that can easily remain hidden if they are not locally discussed.

As a rule, however, educators don't engage in public critical conversations unless these conversations are mediated within the parameters of qualitative research. Even in those cases, because these conversations are admittedly subjective and context specific, findings are often deemed less than valid (Markee, 2000). Circumstances may be changing, however, as more and more individuals, academics and otherwise, are using conversational processes all over the world to bring people together to solve complex multifaceted problems (Argyris \& Schön, 1974; Cashman, Linehan, \& Rosser, 2007).

Emergent empirical methodologies grounded in conversation, such as appreciative inquiry, study circles, and the World Café, are considered later in this chapter. The importance of conversation as a means of understanding is gaining some global validity with organizations such as CIVICUS, an international alliance focused on strengthening civic engagement working out of South Africa and Wheatley's own Berkana Institute serving Third World countries (CIVICUS, 2010; Berkana, 2010). Interdisciplinary thinkers have been cited as conversationalist problem solvers, including Paolo Freire; Anthropologist Angeles Arrien; Physicist and Systems Thinker, Fritjof Capra; and Buddhist teacher, Pema Chödrön. There is a point, however, when the conversation moves from being critical to courageous and then later at some point becoming crucial as in the case for re-visioning an equity agenda addressing the community college achievement gap.

\section{The Need for Courageous Conversations}

Courageous conversations are necessary in relation to access, retention, and completion; students who have the least amount of access, the hardest time staying in school, and the lowest completion rates also happen to be students from underserved backgrounds and frequently students of color. Having discussions about race and student achievement will be uncomfortable and disturbing to some individuals. We are in the United States of America living a shared 
legacy of genocide, slavery, racism, and discrimination. It is a given that having these conversations in one-onone and small group settings will be difficult.

Having conversations of this sort in a larger group may seem even more difficult. However, sometimes a larger group can take the introspective guilt response that is so often found in small group settings away, replacing it with a large group consensual and thus more productive response.

\section{Prerequisites for Courageous Conversations}

For a larger institutional conversation to take place regarding race, language, and culture and their effects on academic achievement, several important conditions need to be in place. First, an administrator, leader, or group of people in power who believe in the process must grant permission, circumstance, and conditions for such dialogue to take place. Second, a facilitator who is well versed on race theory and education needs to be identified so that individual may plan for facilitating the conversation, including goals, intent, and parameters. If the person is unable to understand the assumptions that go with having these conversations or is unable to work within parameters of discomfort, the conversation will not be productive. Third, all participants need to have or come to a quick understanding that race impacts academic achievement. Fourth, all parties need to understand or agree that White people in the United States of America have been the dominant race and have had privileges associated with that domination with express understanding that in the near future White people will not be the majority race in our country (LadsonBillings, 2010). Finally, all parties need to agree to have an honest conversation about race and its impact on academic achievement.

Other conditions such as ground rules and particular ways of addressing participants and reporting the process can be added for which guidelines and constructed exercises are provided as well as tools to inform the conversation. Singleton and Linton (2006) provide many such supports within the resources for their book, Courageous Conversations about Race: A Field Guide for Achieving Equity in School, Crucial Conversations.

For community college settings in particular, these courageous conversations are not only audacious but they are crucial as well. In this case, it might be helpful for courageous conversations to be framed by critical questions that come directly out of the Community College Achievement Gap Model (Nevarez \& Wood, 2010). Some of these questions may be the following: What can institutions do to prevent students from dropping out? What might they do to intervene when there are signs that a student is not being successful? What types of professional development are available for faculty who may not have skills in working with students from traditionally underserved backgrounds? What types of increased instructional technology and resources are available to engage students and supplement their academic achievement? In what ways may community colleges recruit and retain and support researchers, faculty, staff, and leaders who are committed to closing the achievement gap for student at the community college-level? And finally what kinds of campus programs and resources are responsive to the achievement gap found on community college campuses?

Thinking about the questions suggested might also identify feasible outcomes for a conversation about community college gaps. In addition, individuals at the institutional level who may be working in educational opportunity programs or access and retention positions along with educational leaders who are not specifically charged with working with students from underserved backgrounds may join together to form study groups or workgroups focused on improving campus culture, providing opportunities for sense of belonging, investigating financial support, and critically considering campus diversity. Particular focus on extracurricular activities and overall environments that foster cognitive and social development of students should be considered and action steps identified that working groups can begin to put into place.

Thinking about institutional change in response to the academic achievement gap for community college students can seem overwhelming, but there are ways beyond direct conversations specific to race, language, culture, and linguistic diversity that can elicit attainable change with the same positive outcomes. One way is the World Café. 


\section{The World Café}

Recently, I had the opportunity to participate in a World Café experience with roughly 250 others, focused on goals for the graduation initiative on our campus. Teams of eight to 10 worked in table groups on questions that were posed on PowerPoint slides. The goal was for the campus as a whole to think about ways to improve graduation goals for our students. Participants, and this was key, came from every unit on campus; academic, staff, students, and alumni-and were all given equal voice in the Café process.

A facilitator who was also a known expert on educational leadership, cultural proficiency, and race theory familiar with the World Café model led our experience. This individual acted as a timekeeper, taskmaster, and collector of data. Each table had a table facilitator with specific instructions that included making sure each workgroup was on task in terms of addressing the question being posed. All other participants moved from table to table as the questions on the screen changed. Throughout the process participants narrowed their focus and response in terms of reaching campus graduation goals, so that by the time they returned back to their "home table," their original responses had become more focused.

Each table was then asked to come up with a series of bold steps and then asked to post our steps on the walls in the room where the Café was being held. Next, participants were asked to move around the room looking at others posters and selecting the bold steps that most resonated with each individual. At the end of the four-hour session, each person had identified the bold steps that most strongly resonated with what he or she believed were ways in which our campus could feasibly reach our graduation goals; and later (a few weeks later) those bold steps were rank ordered by the number of votes. In the end there were 55 bold steps that participants collectively proposed. Several key themes came out of those bold steps and have been identified as themes that will guide the next step in defining goals and timelines for a large group response to an identified institutional need.

Participants have been publicly addressed, but not individually identified, and thanked for our fourhour working conversation. Now, results from our conversation have been published on a university website and passed on to a steering committee which has begun to identify next steps to address the themes, defining goals and timeline which they will continue communicating with us. As a participant, I have also been invited to participate further throughout this process.

Upon reflection on my participation in this variation of the World Café I thought of ways in which a variety of members from different campuses might come together discuss issues related to the community college achievement gap. I am watching now ways in which my campus community has taken the bold steps identified by a large group of 250 people, who upon second look were in of themselves culturally and linguistically diverse, turned that information over to a steering committee, and watched how that steering committee is identifying next steps to address the themes. I also can see how the themes will define goals and timelines for the future of the initiative. From this experience I now understand that many people's contributions will be included in actions, not just the ideas of one or two educational leaders making a decision, telling us as a community how we are going to reach our graduation goals. The power of buy-in for every individual who was present at the Café experience is great.

What I didn't include about this process was that before we began we discussed the assumptions and the reality that there is a dismal number of students of color and students who are learning English who drop out at our institution by the end of the freshman year. And so, before the World Café took place, there were many courageous conversations around race, ethnicity, and language. There were even conversations about gender, sexual orientation, and racism in general, and ways in which we think about access, retention, and completion and institutional responses or supports to students in our system.

\section{From Conversation to Action}

The following discussion represents my subjective conclusions about the World Café event and call for future mixed methods research. As we have seen, a knowledgeable facilitator can take the reigns, harnessing a diverse crowd of 250, bringing them to near consensus on six themes addressing graduation 
goals and initiatives on a campus is major. I believe had the campus administrative leader in charge been the facilitator, the community would not have responded in the same manner. I believe if we were given assumptions, which we were not, we would have responded differently. I also believe if we were given limitations, which we were not, the outcomes would not have been as strong. As a group we were asked critical questions about who at our institution was achieving success, who was not, and why and then given freedom to dream about ways we would retain the students if we could. We were given permission to converse, dream, and share our visions with one another. It was a liberating exercise.

As a result of having participated in this ongoing conversation, I feel validated. I am a leader in my educational community, and I am particularly interested in leadership that is informed by transformative social justice and educational equity. I believe there is something we can learn from this experience to inform the reconceptualization and even the sustainability of an equity agenda addressing the committee college achievement gap, but we need to take a closer look at what kind of a leader it takes to bring institutional conversations into common practice when it comes to re-visioning change at the community college level as well as policy implications for such practice.

\section{The Call for Critical Leadership}

Addressing issues of social justice is to wrestle with power, access, and academic achievement at every level and in this case, the community college achievement gap (May \& Sleeter, 2010). One of the hallmarks of critical leadership is choosing change as opposed to choosing to change (Santamaria \& Santamaria, 2011). Choosing change means to elect to work for change on a societal level, fully aware that the issues are rooted in institutions. In contrast, choosing to change means individuals conform or assimilate to match the majority because it is either the path of least resistance or because they are altogether unaware that issues even exist. Initiating and engaging in the type of conversation that will yield organic results as opposed to formulaic antiquated practices, as was demonstrated in the Café model described, is one way of deliberately choosing change.
A critical leader, like the main facilitator from the World Café example, fully understands the role of conversation, courageous conversation, and crucial conversation; but most importantly such a leader understands how to take conversation and move it into action. Sitting around and chatting about race, culture, linguistic diversity, and gender inequities is one thing. Facilitating a conversation that will incite change in practice -or thinking about an area where focus has been lost, as in the equity agenda for community colleges- is another.

Critical leadership is unique because it is defined by action. Santamaria and Santamaria (2011) identified three behaviors indicative of critical leaders: 1) These individuals recognize and fully understand critical issues, 2) they convince others that issues are in fact issues (a significant challenge given typical blind spots, denial, and distractions), and 3) they create and sustain a safe space for conversations, reflections, and actions to occur (p. 7).

The main facilitator for the World Café was able to do all of the things identified above. The World Café conversation was not a mere conversation. It led to micro-action and to those actions' being posted on a campus website, which has led to public action. The public action has resulted in changed practice with regard to what we are doing as a campus to retain our student body toward graduation for all students. No one knows how significant the changes will be, but we can agree that some change has indeed occurred. An equity agenda in this case has been revitalized and recreated.

\section{Policy Implications for the Creation of an Equity Agenda}

In thinking about critical leadership with regard to re-visioning an equity agenda in the community colleges, definite steps can be identified to address some of the key concerns. Policy implications for this work are mostly associated with macro level support for the institution and institutional factors.

First, on a national level institutional resources should be set aside to provide institutions with the wherewithal to enable them to re-visit the notion of an equity agenda as a means of addressing the achievement gap indicators identified by Nevarez and 
Wood (2010) with particular attention to remediation, retention, graduation rates, and transfer rates for traditionally underserved students. Specifically, the role of federal support needs to be reevaluated with certain funds set aside to meet the needs of professionals working on these particular goals.

Institutional contributions should be considered in terms of meeting the needs of students impacted by the achievement gap. Also at the institutional level to return attention to an equity agenda, there needs to be some sort of visioning around the re-creation of such an agenda. Administrators need to provide space and support for courageous, crucial, and critical conversations using models such as the World Café. Further, partnerships with LEAs and other institutes of higher education need to be developed and sustained to create a pipeline of students who will thrive in the community college setting and eventually serve the greater needs of the local community, state, nation, and global community. A clear statement indicating high professional standards for all of the individuals who work with students in the college setting should be made.

Finally, on national and institutional levels there should be emphasis on research and evaluation in terms of overall program effectiveness, accountability, and the exploration and consideration of alternative leadership models such as that of critical leadership.

\section{Conclusion}

Coming to a greater understanding of the ways in which achievement indicators influence academic success for students at the community college level requires focused attention and new ways of thinking about old challenges. Just because we know the achievement gap exists and is a part of the education vernacular in the United States of America, does not mean we need to own it or accept it. It is important for educators, researchers, and practitioners to create opportunities to think about re-visioning current equity agendas. As educational and social political landscapes shift, it becomes more and more critical for progressive leaders to think about alternative leadership models like critical leadership and about feasible ways in which to solve pervasive equity related problems such as the achievement gap at every level. Identifying critical leaders who are able to bring diverse groups together to identify solutions is crucial for the future of students at the community college level and beyond. 


\section{REFERENCES}

Advisory Committee on Student Financial Assistance. (2001). Access denied: Restoring the nation's commitment to equal education opportunity. Washington, D.C.: Advisory Committee on Student Financial Assistance.

Anyon, Y. (2009). Sociological theories of learning disabilities: Understanding racial disproportionality in special education. Journal of Human Behavior in the Social Environment, 19(1), 44-57.

Archibald, S., (2006). Narrowing in on educational resources that do affect student achievement. Peabody Journal of Education, 81(4), 23-42.

Argyris, C., \& Schön, D. (1974). Theory in practice. San Francisco: Jossey Bass.

Bailey, T. \& Morest, V. S. (2006). Defending the community college equity agenda. Baltimore, MD: Johns Hopkins Press.

Berkana. (2010). The Berkana institute. Retrieved from: http:// www.berkana.org/

Bowen, W. G., Chingos, M. M., and McPherson, M. S. (2009). Crossing the finish line: Completing college at America's public universities. Princeton, N.J.: Princeton University Press.

Brown, J. \& Isaacs, D. (2005). The world café: Shaping our futures through conversations that matter. San Francisco, CA: Berrett-Koehler Publishing Inc.

California Department of Education (CDE). (2007). State of education address. Retrieved from http://www.cde. ca.gov/eo/in/se/yr07soe.asp

Capps, R., Fix, M., Murray, L., Passel, J. S., \& Herwantoro, S. (2005). The new demography of American schools: Immigration and the No Child Left Behind Act. Washington, DC: The Urban Institute.

Cashman, J., Linehan, P., \& Rosser, M. (2007). Communities of practice: A new approach to solving complex educational problems. Alexandria, VA: National Association of State Directors of Special Education.

CIVICUS (2010). World alliance for citizen participation. Retrieved from: http://www.civicus.org/

Cochran-Smith, M. (2008). The new teacher education in the United States: Directions forward. Teachers and Teaching: Theory and Practice, 14(4), 271-282.

Darling-Hammond, L. (1999). Teacher quality and student achievement: A review of state policy evidence. Center for the Study of Teaching and Policy.
Darling-Hammond, L. (2007). Educational quality and equality: What it will take to leave no child behind. In Brian D. Smedley \& Alan Jenkins (eds.), All Things Being Equal: Instigating Opportunity at an Inequitable Time (pp. 39-78). NY: The New Press, 2007.

Dunn, R., Honigsfeld, A., \& Doolan, L. S. (2009). Instructional strategies on students' achievements and attitudes: Perceptions of educators in diverse institutions. The Clearing House, 82(3), 135-140.

Fullan, M. G. (2001). The new meaning of educational change (3rd ed.). New York, NY: Teachers College Press.

Goldenberg, C. (2008). Teaching English language learners: What the research does and does not say. American Educator, 32(2), 8-11.

Huang, F. L. \& Moon, T. R. (2009). Is experience the best teacher? A multilevel analysis of teacher characteristics and student achievement in low performing schools. Educational Assessment Evaluation Accountability, 21, 209-234.

Kasper, H. T. (2003). The changing role of the community college. Occupational Outlook Quarterly, 46(4), 14-23.

Ladson-Billings, G. (2010). Interdisciplinary research on race in a colorblind era: A critical appraisal and notes on a transformative paradigm. Paper presented at the American Educational Research Association International Conference.

Levin, J. S., \& Montero-Hernandez, V. (2009). Community colleges and their students: Co-construction and organizational identity. New York, NY: Palgrave MacMillan.

Lindsey, R. B., Robins, K. N., \& Terrell, R. D. (1999). Cultural proficiency: A manual for school leaders. Thousand Oaks, CA: Corwin Press.

Lum, L. (2009). The Obama era: A Post-racial society?. Diverse: Issues in Higher Education, 25(26), 14-16.

Markee, N. P. P. (2000). Conversation analysis. Mahwah. NJ: Erlbaum.

May, S., \& Sleeter, C. (2010). Critical multiculturalism: Theory to praxis. New York, NY: Routledge.

Mullin, C. M. (2011). The road ahead: A look at trends in the educational attainment of community college students (Policy Brief 2011-04PBL). Washington, DC: American Association of Community Colleges.

Mullin, C.M. (2012a). Why access matters: The community college student body (Policy Brief 2012-01PBL). Washington, DC: American Association of Community Colleges. 
Mullin, C. M. (2012b). It's a matter of time: Low-income students and community colleges (Policy Brief 2012-02PBL). Washington, DC: American Association of Community Colleges.

Nevarez, C. \& Wood, J. L. (2010) Community college leadership and administration: Theory, practice and change. New York: Peter Lang.

Santamaría, L. J., Santamaría, C. C., \& Fletcher, T. V. (2009). Journeys in cultural competency: Pre-service U.S. teachers in Mexico study-abroad programs. Diaspora, Indigenous, and Minority Education, 3, 32-51.

Santamaría, L. J. \& Santamaría, A. P. (2011). Applied critical leadership in education: Choosing change. New York, NY: Routledge Books.

Shields, C. M. (2010). Transformative leadership: Working toward equity in diverse contexts. Education Administration Quarterly, 46(4), 558-589.

Singleton, G. E., \& Linton, C. (2006). Courageous conversations about race. Thousand Oaks, CA: Corwin.

Vanneman, A., Hamilton, L., Anderson, J., Rahman, T., \& National Center for Education Statistics. (2009). Achievement gaps: How black and white students in public schools perform in mathematics and reading on the national assessment of educational progress. Statistical Analysis Report. (NCES No. 2009-455)

Wheatley, M. (2002). Turning to one another: Simple conversations to restore hope to the future. San Francisco, CA: Berrett-Koehler Publishing Inc.

Yoon, K., Duncan, T., Lee, S., Scarloss, B., \& Shapley, K. (2007). Reviewing the evidence on how teacher professional development affects student achievement. Regional Educational Laboratory at Edvance Research, Inc. (REL No. 2007-No. 033) 
